\title{
Synthesis of Activated Carbon Derived from Garlic Peel and Its Electrochemical Properties
}

\author{
Tongtong Ji, Kuihua Han', Zhaocai Teng, Jinxiao Li, Meimei Wang, Jigang Zhang, \\ Yang Cao, Jianhui Qi
}

Shandong Engineering Laboratory for High-efficiency Energy Conservation and Energy Storage Technology \& Equipment, School of Energy and Power Engineering, Shandong University, Jinan 250061, shandong, China

*E-mail: hankh@163.com

doi: $10.20964 / 2021.01 .61$

Received: 15 June 2020 / Accepted: 30 October 2020 / Published: 30 November 2020

In this paper, hydrochloric acid pretreatment process was used to fabricate the garlic peel-based activated carbon (HGAP) with garlic peel as carbon precursor and $\mathrm{KOH}$ as an activator. The single factor experiment method was used to explore the effects of hydrochloric acid concentration, treatment time, water bath temperature, and carbonization temperature on the pore structure of garlic-based activated carbon. Nitrogen adsorption and desorption, XRD, Raman spectroscopy, constant current charge and discharge, cyclic voltammetry and other characterization methods were used to characterize the physical morphology and electrochemical performance of garlic peel-based activated carbon. The results show that the optimal process conditions for preparing the HGAPs are as follows: heating and stirring in a water bath with $1.0 \mathrm{~mol} / \mathrm{L}$ hydrochloric acid solution at $60^{\circ} \mathrm{C}$ for $3 \mathrm{~h}$, and the carbonization temperature is $600^{\circ} \mathrm{C}$.The specific surface area of HGAP-7 synthesized under the optimal conditions is as high as $3325.2 \mathrm{~m} \mathrm{~g}^{-1}$, and the pore volume is $1.881 \mathrm{~cm}^{3} \mathrm{~g}^{-1}$. Using $6 \mathrm{M} \mathrm{KOH}$ as electrolyte, the supercapacitor assembled by HGAP-7 has a specific capacitance of $424.42 \mathrm{~F} \mathrm{~g}^{-1}$ at a current density of $1 \mathrm{~A} \mathrm{~g}^{-1}$. Compared with non-pretreated garlic peel-based activated carbon, the mesopore contents of HGAPs significantly increase, and the cycle characteristics and rate performance of the supercapacitors are improved.

Keywords: hydrochloric acid pretreatment; garlic peel; activated carbon; supercapacitor

\section{$\underline{\text { FULL TEXT }}$}

(C) 2021 The Authors. Published by ESG (www.electrochemsci.org). This article is an open access article distributed under the terms and conditions of the Creative Commons Attribution license (http://creativecommons.org/licenses/by/4.0/). 